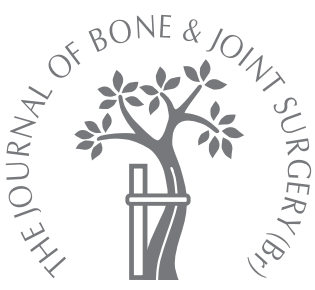

E. K. Song, J. K. Seon, S. J. Park, M. S. Jeong

From Chonnam National Hwasun Hospital, Jeonnam, South Korea

\footnotetext{
E. K. Song, $\mathrm{MD}, \mathrm{PhD}$, Professor

J. K. Seon, MD, PhD Orthopaedic Surgeon S. J. Park, MD, PhD Orthopaedic Surgeon M. S. Jeong, MD, Orthopaedic Surgeon Department of Orthopaedic Surgery

Center for Joint Disease, Chonnam National University Hwasun Hospital, 160 Ilsimri, Hwasun-eup, Hwasun-gun, Jeonnam 519-809, South Korea

Correspondence should be sent to $\operatorname{Dr}$ M. S. Jeong; e-mail: taesado@naver.com

(c)2010 British Editorial Society of Bone and Joint Surgery doi:10.1302/0301-620X.92B9. $23660 \$ 2.00$

$J$ Bone Joint Surg $[\mathrm{Br}]$ 2010;92-B:1245-52. Received 11 October 2009; Accepted after revision 20 April 2010
}

\title{
The complications of high tibial osteotomy
}

\author{
CLOSING- VERSUS OPENING-WEDGE METHODS
}

We compared the incidence and severity of complications during and after closing- and opening-wedge high tibial osteotomy used for the treatment of varus arthritis of the knee, and identified the risk factors associated with the development of complications. In total, 104 patients underwent laterally based closing-wedge and 90 medial opening-wedge high tibial osteotomy between January 1993 and December 2006. The characteristics of each group were similar. All the patients were followed up for more than 12 months. We assessed the outcome using the Hospital for Special Surgery knee score, and recorded the complications. Age, gender, obesity (body mass index $>27.5 \mathrm{~kg} / \mathrm{m}^{2}$ ), the type of osteotomy (closing versus opening) and the pre-operative mechanical axis were subjected to risk-factor analysis.

The mean Hospital for Special Surgery score in the closing and opening groups improved from 73.4 (54 to 86 ) to 91.8 (81 to 100 ) and from 73.8 (56 to 88 ) to 93 (84 to 100), respectively. The incidence of complications overall and of major complications in both groups was not significantly different ( $p=0.20$ overall complication, $p=0.29$ major complication). Logistic regression analysis adjusting for obesity and the pre-operative mechanical axis showed that obesity remained a significant independent risk factor (odds ratio $=3.23$ ) of a major complication after high tibial osteotomy.

Our results suggest that the opening-wedge high tibial osteotomy can be an alternative treatment option for young patients with medial compartment osteoarthritis and varus deformity.

High tibial osteotomy (HTO) is most commonly used in the treatment of isolated osteoarthritis of the medial tibiofemoral compartment. ${ }^{1}$ Treatment for osteochondritis dissecans and condylar osteonecrosis, by unloading the medial compartment or correcting malalignment, are less common indications. ${ }^{2-9}$ It may be performed using a closing-wedge technique, by dome osteotomy, or by an opening-wedge technique. The former, described by Coventry ${ }^{10}$ is the most popular procedure. It may be performed reliably with computer navigation. ${ }^{11}$ Its disadvantages include the risk of injuries to the peroneal nerve and the need for fibular osteotomy or the separation of the proximal tibiofibular joint and the detachment of extensor muscles. Large corrections may compromise later placement of the tibial component during total knee replacement (TKR).

Recently, medial opening-wedge HTO has been favoured over laterally based closing-wedge HTO, because it is simpler, more accurate, allows adjustment in both the coronal and sagittal planes and eliminates the need for fibular osteotomy. Thus, it avoids the risks of damage to the peroneal nerve and fibular pseudarthrosis. ${ }^{3,4,12}$ Also, creating an osteotomy below the tibial tuberosity minimises the risks of development of patella infera, patella subluxation and of the loss of proximal tibial bone stock which may complicate later TKR. ${ }^{13}$ However, it's complications include loss of fixation, nonunion and delayed union because of the relative instability. ${ }^{14-17}$ Although Luites et $\mathrm{al}^{18}$ recently reported similar stability following the two procedures they recommend an opening-wedge technique secured by a Tomofix plate.

Only one study has so far compared the complications of closing- and opening-wedge HTO. ${ }^{15}$ Most have focused on one technique. ${ }^{17,19,20}$ Our aim therefore was to compare the two techniques with respect to intra- and post-operative complications and to identify associated risk factors.

\section{Patients and Methods}

Between January 1993 and December 2006, 194 patients who underwent unilateral closing- or opening-wedge HTO by the senior 
Table I. Clinical details (mean, range) in the two groups

\begin{tabular}{llll}
\hline & Closing-wedge $(\mathbf{n}=\mathbf{1 0 4})$ & Opening-wedge (n = 90) & p-value \\
\hline $\begin{array}{l}\text { Age in years (range) } \\
\text { Gender }\end{array}$ & 57 (37 to 67$)$ & 51 (41 to 67) & 0.312 \\
$\quad \begin{array}{l}\text { Male:female } \\
\text { BMI }\left(\mathrm{kg} / \mathrm{m}^{2}\right)\end{array}$ & $16: 88$ & $21: 69$ & 0.200 \\
Duration of follow-up in month & $28.5(21.2$ to 28.7$)$ & $25.5(20.2$ to 28.9$)$ & 0.057 \\
Mechanical axis of varus $\left({ }^{\circ}\right)$ & $6.5(4.5$ to 12.0$)$ & $26.7(12.0$ to 48.0$)$ & 0.774 \\
Tibial posterior slope $\left(^{\circ}\right)$ & $9.1(4.0$ to 14.0$)$ & $6.8(4.0$ to 13.0$)$ & 0.965 \\
\hline
\end{tabular}

* BMI, body mass index

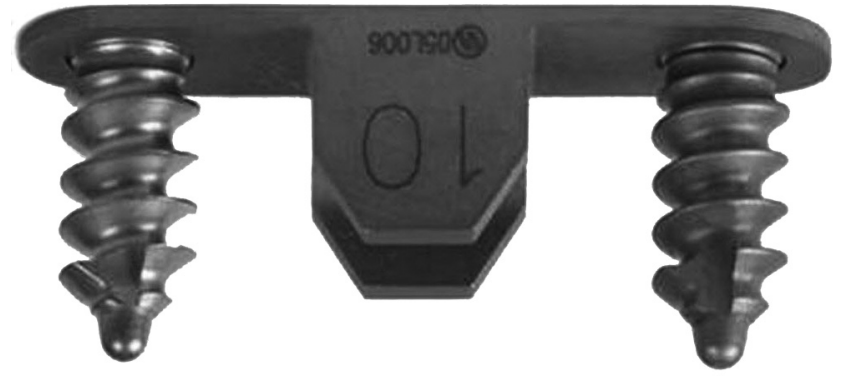

Fig. 1a

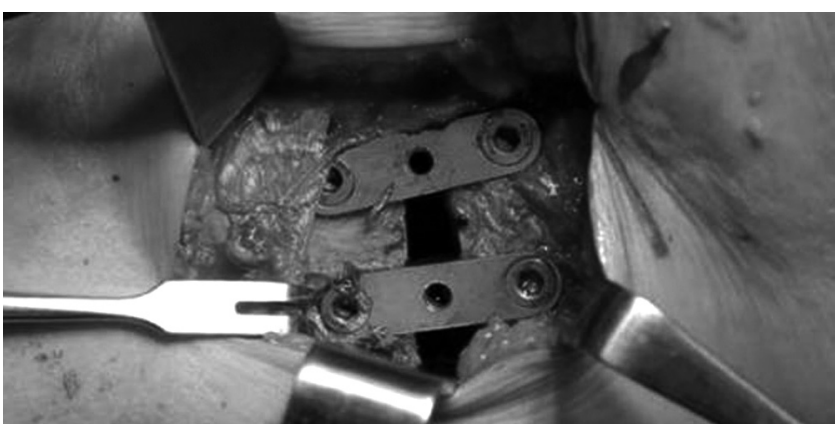

Fig. 1b

Photographs of the Aescula opening-wedge plate system showing a) the plate and screws, and b) intra-operative fixation of the plate.

author (EKS) were enrolled in this retrospective study. All had HTO for medial compartmental osteoarthritis with a varus deformity, with complete medical records and a minimum follow-up of one year. The surgical indications included active patients with a varus arthritic knee in a patient $<70$ years of age, progressive symptoms unresponsive to conservative treatment for at least six months, $>90^{\circ}$ of flexion, a flexion contracture $\leq 10^{\circ}$, intact collateral and cruciate ligaments, no tibiofemoral subluxation and degenerative change which did not exceed Kellgren-Lawrence grade III. ${ }^{21}$ Mild or moderate involvement of the patellofemoral joint was not a contraindication. Patients with symptomatic osteoarthritis involving the lateral compartment and those who smoked or who had undergone combined surgery on the anterior and posterior cruciate ligaments were excluded.

A total of 206 patients was eligible for inclusion; 12 were excluded because of incomplete records. All the patients gave informed consent. The senior author's preference for either type of HTO changed from lateral closing-wedge (January 1993 to October 2003) to medial opening-wedge (November 2003 to December 2006) because of operative convenience and an attempt to reduce complications. In all, 104 lateral closing-wedge and 90 medial opening-wedge osteotomies met the inclusion criteria. The closing-wedge group consisted of 88 women and 16 men with a mean age of 57 years (37 to 67), and the opening-wedge group consisted of 69 women and 21 men with a mean age of 51 years (41 to 67). The mean follow-up in the two groups was 28.3 months (12.0 to 54.0) and 26.7 months (12.0 to 48.0), respectively (Table I). Pre-operative templating to determine the extent of the correction was performed based on the method described by Dugdale, Noyes and Styer ${ }^{22}$ and Noyes, Barber-Westin and Roberts. ${ }^{23}$

Operative technique. The patient was positioned supine on a radiolucent operating table. A thigh tourniquet was applied and the leg draped free. Preliminary diagnostic arthroscopy of the knee was performed. Fluoroscopy was used to identify the lateral tibial plateau, to control the osteotomy and to check alignment during surgery. Closingwedge osteotomies were stabilised using two staples and opening-wedge osteotomies by two open-wedge Aescula plates (B. Braun-Aesculap, Melsungen, Germany; Fig. 1).

Closing-wedge group. Osteotomy was performed as follows using a lateral approach. The common peroneal nerve was exposed and retracted, the proximal tibiofibular joint was opened and the osteotomy was constructed based on the pre-operative plan. The proximal surface of the osteotomy was marked with a Kirschner (K)-wire introduced roughly horizontally and about $2 \mathrm{~cm}$ below the tibial pla- 


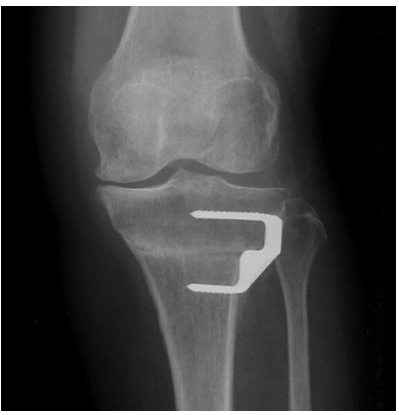

Fig. 2a

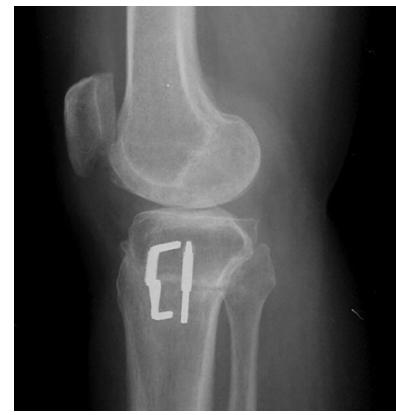

Fig. $2 b$

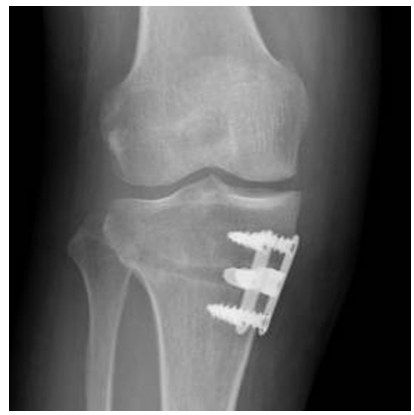

Fig. 3a

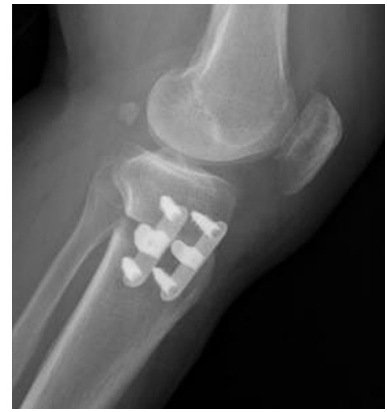

Fig. 3b

Anteroposterior a) and lateral b) radiographs of a closing-wedge high tibial osteotomy stabilised by two staples.

teau. A second K-wire was placed below the first to mark the distal aspect of the osteotomy. The angle formed between the two equalled the angle of the proposed osteotomy. Placement of the K-wires was performed under fluoroscopic guidance. The first saw cut was made under the first K-wire with the saw slightly tilted to match the patient's posterior tibial slope. The posterior cortex was left intact, as described by Slocum et al. ${ }^{24}$ The second saw cut was made above the second $\mathrm{K}$-wire to cross only about $75 \%$ of the width of the tibia. A thin saw blade was then used to separate the tibial tuberosity from the metaphysis. The tuberosity was left attached to the distal fragment. After removing the outer wedge of bone, osteotomes and curettes were used to ensure that the medial periosteal sleeve and cortex were intact. In order to assist this, the medial cortex was perforated by a drill or osteotome, as required. The medial cortex had to be broken if the angular correction was large. The distal fragment was abducted to close the osteotomy. As described by Slocum et $\mathrm{al}^{24}$ we left a thin posteromedial overhang of bone on the proximal tibial fragment. This posterior lip overrode the proximal end of the distal fragment and provided added support and stability to the osteotomy. The correction and mechanical axis were verified by fluoroscopy. The alignment was adjusted to achieve the desired correction and the fragments were secured with two stepped staples (Fig. 2).

Opening-wedge group. A skin incision of between $3 \mathrm{~cm}$ and $6 \mathrm{~cm}$ was made anteromedially on the proximal tibia. Dissection through the sartorial fascia was performed to expose the tendons of gracilis and semitendinous, which were then retracted distally. The posterior third of the superficial medial collateral ligament was reflected, and the anterior two-thirds incised transversely in line with the intended osteotomy. In view of the possibility of fracture of the lateral cortex because of the application of excessive valgus force to achieve a medial opening, the medial soft tissues were released to allow completion of the posterior corticotomy. A $3.0 \mathrm{~mm}$ guide wire was then inserted obliquely, after identifying the tibial tuberosity, to prevent the osteotomy extending into it. An oblique tibial

tuberosity osteotomy was performed with a chisel to prevent injury to the patellar ligament. In order to obtain stability of the osteotomy, an incomplete valgus opening-wedge procedure was performed leaving $5 \mathrm{~mm}$ of the lateral tibial cortex intact. In order to avoid intra-articular damage, the osteotomy was carefully exposed by the stepwise insertion of three coupled osteotomes. An appropriate sized plate was selected; the first plate was inserted at the posteromedial corner as posteriorly as possible, and the second plate at the anteromedial corner behind the osteotomy of the tuberosity. In order to maintain the posteror tibial slope, the opening wedge was trapezoidal rather than rectangular in the sagittal plane, such that the anterior gap of the osteotomy was approximately two-thirds of the posterior gap as has been previously described. ${ }^{25-28}$ If the posterior opening-wedge was more than $7.0 \mathrm{~mm}$, the open gap was filled with $15 \mathrm{ml}$ of cancellous allograft bone obtained from TranZgraft (Tissue Banks International, Baltimore, Maryland) (Fig. 3).

In both groups, prophylaxis for deep-vein thrombosis (DVT) included the administration of low-molecularweight heparin (5000 units subcutaneously daily) for one week, immediate flexion exercises, and the wearing of antiembolism stockings. Doppler ultrasound was performed if a patient had abnormal calf tenderness, or increased oedema.

Post-operative rehabilitation. In the closing-wedge group, a non-weight bearing above-knee plaster cast was retained for the first two to three weeks after which active exercises with a brace were started. Partial weight-bearing was allowed at six weeks post-operatively and full weightbearing at eight to 12 weeks post-operatively.

In the opening-wedge group, isometric quadriceps and active ankle exercises were begun immediately after surgery. Active exercises, patellar mobilisation and straightleg raises were started on the first post-operative day. Partial weight-bearing was allowed at six weeks, and full weight-bearing at eight to 12 weeks post-operatively. A knee brace was used for about eight weeks until weightbearing was begun. 
Evaluation. Complications were recorded at every stage. At each visit the range of movement was measured using a goniometer by one observer (MSJ) and functional assessment was performed using the Hospital for Special Surgery (HSS) ${ }^{29}$ knee score. Radiological evaluation was carried out on the first and 14th post-operative days and then monthly until the osteotomy had united as shown on standard anteroposterior (AP) and lateral radiographs. Long-leg standing radiographs were taken to assess alignment pre-operatively, monthly after bony healing and at the final follow-up. Alignment with respect to the mechanical axis (hip-knee-ankle angle) and the tibial posterior slope were compared using lateral radiographs at 12 weeks post-operatively and at final follow-up. The films were studied for evidence of nonunion, failure of hardware or fixation and loss of correction. Loss of angular correction was defined as a loss of the mechanical axis $\geq 3^{\circ}$ between the alignment at 12 weeks post-operatively and at the last follow-up.

The hip-knee-ankle angle (mechanical axis angle) was defined as that formed between a line transecting the centre of the femoral head to the centre of the knee and a line transecting the centre of the knee to the centre of the ankle. The posterior tibial slope was defined as the angle between the tangent drawn across the articular surface of the proximal plateau and a line drawn perpendicular to the tibial shaft axis.

The clinical indicators used to assess the progress of union were pain on movement or weight-bearing, tenderness and warmth on palpation, or swelling at the site of an osteotomy. The radiological indicators used to assess union were increasing graft density on serial examinations and trabecular bridging across the osteotomy. Signs of nonunion were an absence of the above indicators at six months post-operatively and a sclerotic margin at the periphery of an osteotomy. Other major complications, such as injury to the common peroneal or tibial nerve compartment syndrome or deep infection, failure of hardware or fixation, loss of correction and fracture of the tibial plateau were identified from the medical records. Complications such as sensory changes, superficial wound infection, flexion contracture of more than $10^{\circ}$ and skin irritation caused by underlying metal, were also evaluated but considered to be minor because they were easily treated and did not result in any disability or re-operation.

Risk factor analysis included age, gender, obesity (body mass index $(\mathrm{BMI})>27.5 \mathrm{~kg} / \mathrm{m}^{2}$ ), the type of osteotomy (closing versus opening) and the pre-operative mechanical axis. Statistical analysis. Statistical comparisons between preoperative and final follow-up data were performed using the paired-samples $t$-test using SPSS version 17.0 software (SPS Inc., Chicago, Illinois). The independent-samples $t$-test was used to compare HSS scores and the chi-squared test to compare complications. A p-value $\leq 0.05$ was considered to be significant. Multivariate logistic regression with stepwise variable selection was performed to determine the influence of age, gender, obesity (BMI), the type of osteotomy (closing versus opening), and the pre-operative mechanical axis. Factors found to be associated with the incidence of a major complication at a $p$-level $\leq 0.1$ by univariate analysis were included in the multivariate logistic regression model. For uni- and multivariate analysis the odds ratios and the $95 \%$ confidence intervals (CI) were calculated. Statistical significance for the multivariate model was accepted when the p-value was $<0.05$.

\section{Results}

No significant differences in the clinical details were found between the two groups (Table I). The mean pre- and postoperative range of movement, the duration to union of the osteotomy, pre- and post-operative HSS score and the postoperative mechanical axis were not significantly different in the two groups (Table II). In six knees (four in the closing group and two in the opening group) a flexion contracture of between $10^{\circ}$ and $15^{\circ}$ was found post-operatively. The mean post-operative tibial slope in the closing and opening groups was $4.6^{\circ}\left(1.0^{\circ}\right.$ to $\left.11.0^{\circ}\right)$ and $10.4^{\circ}\left(7.0^{\circ}\right.$ to $\left.14.0^{\circ}\right)$, respectively, which was statistically significant $(\mathrm{p}=0.032)$. The mean pre-operative tibial slope was $9.1^{\circ}\left(4^{\circ}\right.$ to $\left.14^{\circ}\right)$ and $9.5^{\circ}$ $\left(6^{\circ}\right.$ to $\left.13^{\circ}\right)(\mathrm{p}=0.891)$. Further analysis showed that the mean posterior slope changed significantly in the closing group ( $p=0.042)$, but not in the opening group $(p=0.405$; Table II). Overall and major complications occurred in $29(27.9 \%)$ and $17(16.4 \%)$ knees, respectively in the closing-wedge group and $18(20.0 \%)$ and $10(11.1 \%)$, respectively, in the opening-wedge group. The incidence of overall and major complications in the two groups was not significantly different $(\mathrm{p}=0.201, \mathrm{p}=0.293)$. There were two knees with multiple complications in the closing wedge and one knee in the opening group. However, of those complications, only one complication of greater severity was recorded.

In the closing-wedge group, the following major complications occurred; seven injuries to the common peroneal nerve, two cases of compartment syndrome, one deep infection, two nonunions, one failure of fixation, two cases of loss of correction and two of a varus instability. By contrast, in the opening-wedge group there were two cases of failure of fixation, two of loss of correction and six fractures of the lateral tibial plateau (Table III). Minor complications included six injuries to a sensory nerve (two in the closing group and four in the opening group), two superficial wound infections in the closing-wedge group, six flexion contractures over $10^{\circ}$ (four in the closing and two in the opening group), two episodes of skin irritation in the opening group, and four cases of fibular nonunion in the closing group; Table III). In the closing-wedge group, the two patients with nonunion, the one with fixation failure and the two with loss of correction were treated by re-operation using $90^{\circ}$ adolescent three-hole hip plates (OSTEO, Selzach, Switzerland), which allowed union to occur with a stable knee. The outcome of the two patients with compartment syndrome was that one fully recovered after an immediate fasciotomy, but the other was diagnosed late and underwent arthrodesis of the ankle for an equinus 
Table II. Details of the results (mean and range as appropriate) in the two groups

\begin{tabular}{|c|c|c|c|}
\hline & Closing-wedge ( $n=104)$ & Opening-wedge $(n=90)$ & p-value \\
\hline \multicolumn{4}{|l|}{ Range of movement $\left({ }^{\circ}\right)$} \\
\hline \multicolumn{4}{|l|}{ Pre-operative } \\
\hline Extension angle & 4.1 (0 to 9$)$ & 3.78 (0 to 9$)$ & 0.119 \\
\hline Flexion angle & $135 \quad$ (115 to 155$)$ & $138 \quad$ (116 to 154$)$ & 0.145 \\
\hline \multicolumn{4}{|l|}{ Post-operative } \\
\hline Extension angle & $3.3(0$ to 12$)$ & $3.2(0$ to 12$)$ & 0.182 \\
\hline Flexion angle & $136 \quad$ (115 to 156$)$ & 138 (117 to 154$)$ & 0.147 \\
\hline Duration of bony union (weeks) & $12.9(9.1$ to 15.0$)$ & $12.3(10.4$ to 16.8$)$ & 0.736 \\
\hline \multicolumn{4}{|l|}{ HSS $^{*}$ knee score (points) } \\
\hline Pre-operative & 73.4 (54 to 86$)$ & $73.8(56$ to 88$)$ & 0.854 \\
\hline Post-operative & 91.8 (81 to 100$)$ & $93.0(84$ to 100$)$ & 0.683 \\
\hline Mechanical axis in valgus $\left({ }^{\circ}\right)$ & 2.5 (1 to 7 ) & 2.8 (1 to 6$)$ & 0.562 \\
\hline \multicolumn{4}{|l|}{ Tibial posterior slope $\left({ }^{\circ}\right)$} \\
\hline Pre-operative & 9.1 (4 to 14$)$ & 9.5 (6 to 13$)$ & 0.891 \\
\hline Post-operative & $4.6(1$ to 11$)$ & 10.4 (7 to 14$)$ & 0.032 \\
\hline
\end{tabular}

Table III. Details of complications in the two groups

\begin{tabular}{|c|c|c|c|}
\hline & Closing-wedge $(n=104)$ & Opening-wedge $(n=90)$ & p-value \\
\hline \multicolumn{4}{|l|}{ Complications } \\
\hline Major (\%) & $17(16.3)$ & $10(11.1)$ & 0.293 \\
\hline Major nerve injury & 7 & 0 & \\
\hline Compartment syndrome & 2 & 0 & \\
\hline Deep infection & 1 & 0 & \\
\hline Nonunion & 2 & 0 & \\
\hline Fixation failure & 1 & 2 & \\
\hline Loss of correction & 2 & 2 & \\
\hline Instability & 2 & 0 & \\
\hline Tibial plateau fracture & 0 & 6 & \\
\hline Minor (\%) & $12(11.5)$ & $8(8.9)$ & \\
\hline Sensory nerve injury & 2 & 4 & \\
\hline Superficial wound infection & 2 & 0 & \\
\hline Flexion contracture $>10^{\circ}$ & 4 & 2 & \\
\hline Skin irritation & 0 & 2 & \\
\hline Fibular nonunion & 4 & 0 & \\
\hline Overall (\%) & $29(27.9)$ & $18(20.0)$ & $0.201^{*}$ \\
\hline
\end{tabular}

* Pearson's chi-squared test

deformity. One patient developed a deep infection with Staph. epidermis which was successfully managed by removal of the staples and intravenous ampicillin $(1.5 \mathrm{~g})$ for three weeks. The two knees with varus instability were treated by reconstruction of the lateral collateral ligament. In the closing-wedge group, seven patients had nerve injuries, two involving the common peroneal nerve damage, three the deep peroneal nerve palsy, and two the superficial peroneal nerve. In each case a foot-ankle orthosis was applied, and six fully recovered in six months. One underwent arthrodesis of the ankle and was satisfied at the last follow-up.
In the opening-wedge group, the two patients with failure of fixation and the two with loss of correction were treated by re-operation using an LCP (locking compression plate Synthes, West Chester, Pennsylvania) and valgus realignment was eventually obtained. The undisplaced fractures of the tibial plateau were treated by application of a cast for four weeks and the displaced fractures by an additional cannulated screw. They healed without any complications (Fig. 4). The dorsal cutaneous branch of the superficial peroneal nerve was affected in the closing group and infrapatellar branch of the saphenous nerve in the opening group. 


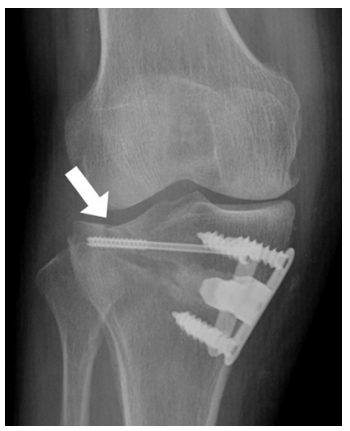

Fig. 4a

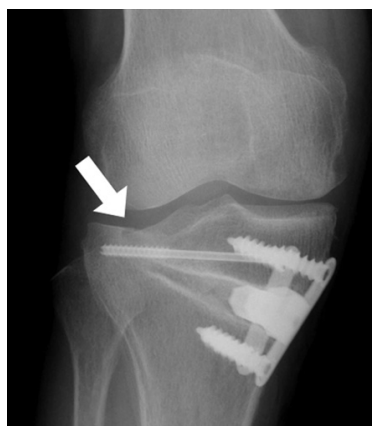

Fig. $4 b$

Radiographs of a fracture extending to the lateral tibial plateau during medial opening-wedge high tibial osteotomy which was a) stabilised by an additional $4.0 \mathrm{~mm}$ cannulated screw (arrow $=$ fracture site) and b) healed at three months after the initial surgery (arrow = union of fracture).

Table IV. Univariate analysis of the risk factors of major complications during and after high tibial osteotomy

\begin{tabular}{lll}
\hline & \multicolumn{2}{l}{ Univariate analysis } \\
\cline { 2 - 3 } Risk factor & Odds ratio (95\% $\left.\mathbf{C l}^{*}\right)$ & p-value \\
\hline Age $(\geq 60$ years) & $1.741(0.775$ to 3.909$)$ & 0.176 \\
Gender (male) & $0.947(0.334$ to 2.686$)$ & 0.918 \\
$\mathrm{BMI}^{\dagger}\left(27.5 \mathrm{~kg} / \mathrm{m}^{2}\right)$ & $3.199(1.411$ to 7.255$)$ & 0.004 \\
Operation type (opening-wedge) & $0.597(0.260$ to 1.371$)$ & 0.293 \\
Pre-operative mechanical axis $\left(\geq\right.$ varus $\left.10^{\circ}\right)$ & $3.490(1.477$ to 8.249$)$ & 0.003 \\
\hline * Cl, confidence interval & & \\
$\dagger$ BMI, body mass index & & \\
$\ddagger$ Univariate logistic regression analysis & &
\end{tabular}

Univariate analysis showed that obesity and pre-operative mechanical axis ( $\geq$ varus of $10^{\circ}$ ) were associated with a major complication (odds ratio $=3.199,3.490, \mathrm{p}=0.004$, $\mathrm{p}=0.003$ respectively), (Table IV). Multivariate analysis showed that obesity was a significant independent predictor of a major complication (odds ratio $=3.230,95 \%$ CI 1.605 to $6.501, \mathrm{p}=0.001$ ), whereas the pre-operative mechanical axis was not a risk factor (odds ratio $=0.644,95 \%$ CI 0.292 to $1.423, \mathrm{p}=0.277$ ).

\section{Discussion}

Jackson and Waugh ${ }^{28}$ first introduced the concept of HTO for the treatment of osteoarthritis of the knee and the technique was later popularised by Coventry. ${ }^{10}$ Although opening-wedge HTO has become popular in recent years because it minimises the disadvantages of lateral closingwedge osteotomy, including injury to the peroneal nerve, ${ }^{30}$ disruption of the proximal tibiofibular joint and lateral ligament and compartment syndrome, this procedure has not gained wide popularity because of its disadvantages. These include failure of fixation, loss of correction, nonunion and delayed union. Several studies have shown that opening-wedge osteotomy has a higher rate of complications than closing-wedge osteotomy. Van den Bekerom et al $^{15}$ reported that the overall complication rate for opening-wedge HTO (55\%; 11 of 20$)$ using a Puddu plate was significantly greater than that for closing-wedge HTO $(20 \%$; 4 of 20$)$ using an AO/ASIF Lplate. Brouwer et al $^{17}$ reported a major complication rate of $4 \%$ ( 4 of 47 ) for closing-wedge HTO using two staples, but of $11 \%$ ( 8 of 45 ) for opening-wedge HTO using a Puddu plate. However, in our study, the overall rate of complications for the closing group of $27.9 \%$ was greater than that for the opening group $(20.0 \%)$, although this difference was not significant. Furthermore, we found no correlation between the type of osteotomy (closing versus opening-wedge; $16.4 \%$ and $11.1 \%$ ) and the incidence of major complications by univariate analysis.

We found a decreased posterior tibial slope after a closing-wedge procedure and an increased slope after the opening-wedge procedure. This is in agreement with the findings of El-Azab et al. ${ }^{31}$ The clinical significance of the changes remains uncertain.

Many cases of injury to the peroneal nerve during closing-wedge osteotomy have been attributed to the improper detachment of muscle from the lateral side of 
the proximal tibia or the improper placement of or excessive pressure applied by a retractor during proximal tibiofibular disruption. ${ }^{32}$ In our study, the rate of injury to the peroneal nerve during closing-wedge osteotomy was $6.7 \%$ (7 of 104), but with medial opening-wedge HTO this complication was avoided. We did not encounter nonunion after opening-wedge HTO, although failure of fixation and loss of correction occurred in $4.4 \%$ of patients (4 of 90). On the other hand, van den Bekerom et $\mathrm{al}^{15}$ and Spahn ${ }^{16}$ reported a higher rate of nonunion and failure of fixation when a Puddu plate was used in opening-wedge osteotomy.

Several factors may have contributed to the low rate of fixation failure and loss of correction observed in our study. First, to prevent displacement of the lateral cortex during opening-wedge HTO, we attempted to save $5 \mathrm{~mm}$ to $10 \mathrm{~mm}$ of lateral bone when performing the osteotomy, and proceeded slowly with the opening procedure. Secondly, we used a two-plate rather than a single-plate system, whereby one plate was inserted anteriorly and the other posteriorly allowing three-point fixation between the two plates and the unharmed lateral cortex. This provided good stability. Thirdly, to minimise the risk of fracturing the tibial plateau we released the soft-tissues medially and performed the osteotomy parallel to the posterior tibial slope in the sagittal plane. In the opening group, six fractures of the lateral tibial plateau occurred because of a technical error such as leaving too much lateral cortex intact and creating an osteotomy which was not parallel to the tibial slope. Lastly, we tried not to break the medial cortex at the site of the osteotomy to avoid collapse and recurrence of deformity. However, despite these efforts, loss of correction occurred because of intra-operative breakage of the medial cortex, despite post-operative immobilisation.

The Aescula plate has several advantages over the TomoFix (Synthes) and Puddu (Arthrex, Naples, Florida) plates; it is small, thin, and pliable. It minimises medial soft-tissue injury and prevents skin irritation. In our study only two of the 90 patients had skin irritation compared with greater numbers for the other devices in previous reports. ${ }^{17,33}$

The relationship between complications and the wedge size for correction has been reported elsewhere. ${ }^{34,35} \mathrm{Nel}$ issen, van Langelaan and Nelissen ${ }^{36}$ reported significantly more complications in patients treated by opening-wedge HTO of $>10 \mathrm{~mm}$.

In our study, we found a correlation between obesity and the pre-operative mechanical axis and peri-operative major complications in both groups by univariate analysis. However, a BMI of more than $27.5 \mathrm{~kg} / \mathrm{m}^{2}$ was found to be the only significant independent predictor of a major complication by logistic regression analysis after adjusting for the pre-operative mechanical axis.

We recognise that our study has limitations because of its retrospective nature and the patient groups being treated during different periods. However, this latter concern would have minimised selection bias.
We recommend opening-wedge $\mathrm{HTO}$ as an alternative treatment option for young patients with medial compartment osteoarthritis and varus deformity.

No benefits in any form have been received or will be received from a commercal party related directly or indirectly to the subject of this article.

\section{References}

1. Akizuki S, Shibakawa A, Takizawa T, Yamazaki I, Horiuchi H. The long-term outcome of high tibial osteotomy: a ten-to 20-year follow-up. J Bone Joint Surg [Br] 2008;90-B:592-6.

2. Coventry MB. Upper tibial osteotomy. Clin Orthop 1984;182:46-52.

3. Amendola A, Panarella L. High tibial osteotomy for the treatment of unicompartmental arthritis of the knee. Orthop Clin North Am 2005;36:497-504.

4. Dowd GS, Somayaji HS, Uthukuri M. High tibial osteotomy for medial compartment osteoarthritis. Knee 2006;13:87-92

5. Hernigou P, Medevielle D, Debeyre J, Goutallier D. Proximal tibial osteotomy for osteoarthritis with varus deformity: a ten to thirteen-year follow-up study. J Bone Joint Surg [Am] 1987;69-A:332-54.

6. Marti CB, Gautier E, Wachtl SW, Jakob RP. Accuracy of frontal and sagittal plane correction in open-wedge high tibial osteotomy. Arthroscopy 2004;20:36672.

7. Parker DA, Viskontas DG. Osteotomy for the early varus arthritic knee. Sports Med Arthrosc 2007;15:3-14.

8. Noyes FR, Barber-Westin SD, Hewett TE. High tibial osteotomy and ligament reconstruction for varus angulated anterior cruciate ligament-deficient knees. Am J Sports Med 2000;28:282-96.

9. Brinkman JM, Lobenhoffer P, Agneskirchner JD, et al. Osteotomies around the knee: patient selection, stability of fixation and bone healing in high tibial osteotomies. J Bone Joint Surg [Br] 2008;90-B:1548-57.

10. Coventry MB. Osteotomy of the upper portion of the tibia for degenerative arthritis of the knee: a preliminary report. J Bone Joint Surg [Am] 1965;47-A:984-90.

11. Bae DK, Song SJ, Yoon KH. Closed-wedge high tibial osteotomy using computerassisted surgery compared to the conventional technique. J Bone Joint Surg [Br] 2009;91-B:1164-71.

12. Spahn G, Wittig R. Primary stability of various implants in tibial opening wedge osteotomy: a biomechanical study. J Orthop Sci 2002;7:683-7.

13. Meding JB, Keating EM, Ritter MA, Faris PM. Total knee arthroplasty after high tibial osteotomy: a comparison study in patients who had bilateral total knee replacement. J Bone Joint Surg [Am] 2000;82-A:1252-9.

14. Stuart MJ, Beachy AM, Grabowski JJ, An KN, Kaufman KR. Biomechanical evaluation of a proximal tibial opening-wedge osteotomy plate. Am J Knee Surg 1999;12:148-53

15. van den Bekerom MP, Patt TW, Kleinhout MY, van der Vis HM, Albers GH. Early complications after high tibial osteotomy: a comparison of two techniques. J Knee Surg 2008;21:68-74.

16. Spahn G. Complications in high tibial (medial opening wedge) osteotomy. Arch Orthop Trauma Surg 2004;124:649-53.

17. Brouwer RW, Bierma-Zeinstra SM, van Raaij TM, Verhaar JA. Osteotomy for medial compartment arthritis of the knee using a closing wedge or an opening wedge controlled by a Puddu plate: a one-year randomised, controlled study. J Bone Joint Surg [Br] 2006;88-B:1454-9.

18. Luites JW, Brinkman JM, Wynenga AB, van Heerwaarden RJ. Fixation stability of opening- versus closing-wedge high tibial osteotomy: a randomised clinical trial using radiosterometry. J Bone Joint Surg [Br] 2009;91-B:1459-65.

19. Magyar G, Ahl TL, Vibe P, Toksvig-Larsen S, Lindstrand A. Open-wedge osteotomy by hemicallotasis or the closed-wedge technique for osteoarthritis of the knee: a randomised study of 50 operations. J Bone Joint Surg [Br] 1999:81B:444-8.

20. Adili A, Bhandari M, Giffin R, Whately C, Kwok DC. Valgus high tibial osteotomy: comparison between an llizarov and a Coventry wedge technique for the treatment of medial compartment osteoarthritis of the knee. Knee Surg Sports Traumatol Arthrosc 2002;10:169-76.

21. Kellgren JH, Lawernce JS. Radiological assessment of osteo-arthrosis. Ann Rheum Dis 1957;16:494-502.

22. Dugdale TW, Noyes FR, Styer D. Preoperative planning for high tibial osteotomy: the effect of lateral tibiofemoral separation and tibiofemoral length. Clin Orthop 1992;274:248-64.

23. Noyes FR, Barber-Westin SD, Roberts CS. High tibial osteotomy in knees with associated chronic ligament deficiencies. In: Jackson DW, ed. Master techniques in orthopaedic surgery: reconstructive knee surgery. Second ed. Philadelphia: Lippincott Williams \& Wilkins, 2003:229-60. 
24. Slocum DB, Larson RL, James SL, Grenier R. High tibial osteotomy. Clin Orthop 1974; 104:239-43.

25. Song EK, Seon JK, Park SJ. How to avoid unintended increase of posterior slope in navigation-assisted open-wedge high tibial osteotomy. Orthopedics 2007;30(Suppl):127-31.

26. Giffin JR, Vogrin TM, Zantop T, Woo SL, Harner CD. Effects of increasing tibial slope on the biomechanics of the knee. Am J Sports Med 2004;32:376-82.

27. Marti RK, Verhagen RA, Kerkhoffs GM, Moojen TM. Proximal tibial varus osteotomy: indications, technique, and five to twenty-one-year results. J Bone Joint Surg [Am] 2001;83-A:164-70.

28. Jackson JP, Waugh W. Tibial osteotomy for osteoarthritis of the knee. J Bone Joint Surg [Br] 1961;43-B:746-51.

29. Insall JN, Ranawat CS, Aglietti P, Shine J. A comparison of four models of total knee-replacement prosthesis. J Bone Joint Surg [Am] 1976;58-A:754-65.

30. Sundaram NA, Hallett JP, Sullivan MF. Dome osteotomy of the tibia for osteoarthritis of the knee. J Bone Joint Surg [Br] 1986;68-B:782-6.
31. El-Azab H, Halawa A, Anetzberger H, Imhoff AB, Hinterwimmer S. The effect of closed- and open-wedge high tibial osteotomy on tibial slope: a retrospective radiological review of 120 cases. J Bone Joint Surg [Br] 2008;90B:1193-7.

32. Georgoulis AD, Makris CA, Papageorgiou CD, et al. Nerve and vessel injuries during high tibial osteotomy combined with distal fibular osteotomy: a clinically relevant anatomic study. Knee Surg Sports Traumatol Arthrosc 1999;7:15-19.

33. Takeuchi R, Ishikawa $\mathbf{H}$, Aratake $\mathbf{M}$, et al. Medial opening wedge high tibial osteotomy with early full weight bearing. Arthroscopy 2009;25:46-53.

34. Wilson NA, Scherl SA, Cramer KE. Complications of high tibial osteotomy with external fixation in adolescent Blount's disease. Orthopedics 2007;30:848-52.

35. Miller BS, Downie B, McDonough EB, Wojtys EM. Complications after medial opening wedge high tibial osteotomy. Arthroscopy 2009;25:639-46.

36. Nelissen EM, van Langelaan EJ, Nelissen RG. Stability of medial opening wedge high tibial osteotomy: a failure analysis. Int Orthop 2010;34:217-23. 